\title{
The Reactions of Carbon Monoxide Catalytic Oxidation on Ti and Zr-embedded Graphene, a DFT Study
}

\author{
Fengming XIE ${ }^{1}$, Jiawei JIANG ${ }^{1}$, Jiyu TANG $^{1}$, Jia LU ${ }^{1}$, Guoliang DAI ${ }^{1 *}$, Gangling CHEN $^{2}$ \\ ${ }^{1}$ Jiangsu Key Laboratory for Environment Functional Materials, School of Chemistry Biology and Material Engineering, \\ Suzhou University of Science and Technology, Suzhou 215009, P. R. China \\ ${ }^{2}$ School of Material Science and Chemical Engineering, Chuzhou University, Chuzhou 239000, P. R. China \\ crossref http://dx.doi.org/10.5755/j01.ms.25.2.19437
}

Received 08 November 2017; accepted 22 March 2018

\begin{abstract}
Density functional theory (DFT) calculations have been performed to explore the mechanistic aspects of the catalytic oxidation of $\mathrm{CO}$ over $\mathrm{Ti}$ and $\mathrm{Zr}$-embedded graphene. The present results show that the title reactions start with the activation of an oxygen molecule as: $\mathrm{O}_{2} \rightarrow \mathrm{O}_{2}$ act. The $\mathrm{CO}$ oxidation over the catalyst surface proceeds through the following elementary steps: (a) $\mathrm{O}_{2 \text { act }}+\mathrm{CO} \rightarrow \mathrm{CO}_{2}+\mathrm{O}_{\text {ads }}$; (b) $\mathrm{O}_{\text {ads }}+\mathrm{CO} \rightarrow \mathrm{CO}_{2}$. Both the Ti and Zr-embedded graphene show good catalytic activity toward the $\mathrm{CO}$ oxidation via the ER mechanism with a three-step route. The present results may be helpful in understanding the mechanism of $\mathrm{CO}$ oxidation over metal-decorated graphene and further experimental design of low-cost catalyst in $\mathrm{CO}$ emission.

Keywords: DFT, NBO, titanium, zirconium, graphene.
\end{abstract}

\section{INTRODUCTION}

As one of the main poisonous gases from the combustion of fuel, vehicles and industrial process, carbon monoxide pose a serious threat to the health of living organisms and ecosystems. Nowadays, it has become one of the most challenging subjects to monitor and remove this toxic gas from industrial and domestic emissions quickly and efficiently. In the past many years, considerable attention has been paid to convert this species into nontoxic $\mathrm{CO}_{2}$. Catalytic oxidation is one of the effective routes to remove this undesired hazardous molecule [1]. In previous years, some types of noble metals such as $\mathrm{Pd}, \mathrm{Pt}, \mathrm{Ru}, \mathrm{Rh}, \mathrm{Ag}, \mathrm{Au}$ were used as effective catalysts for $\mathrm{CO}$ oxidation [2-12], but the high cost limits their widespread use in practical application. According to the recent studies, much interest has been focused on the experimental and theoretical studies of metal-free and non-noble metal-embedded graphene, which shows better performance for the $\mathrm{CO}$ oxidation but with a relatively lower cost [13-24], indicating such complexes have potential for practical application in oxidation of $\mathrm{CO}$. $\mathrm{Li}$ et al. have investigated the catalytic oxidation of CO over Iron-embedded graphene by means of first-principles computations [15], they found the $\mathrm{Fe}$ embedded graphene show good catalytic activity for the $\mathrm{CO}$ oxidation via the more favorable Eley-Rideal (ER) mechanism. Limtrakul et al. have theoretically investigated the oxidation of carbon monoxide using nitrous oxide as an oxidizing agent on Fe-graphene [16], their results show the high catalytic activities of Fe-embedded graphene toward $\mathrm{CO}$ oxidation, and the graphene sheet play an important role during the reaction progress. Esrafili et al. have examined the reaction of $\mathrm{CO}$ oxidation by $\mathrm{O}_{2}$ over Al-, $\mathrm{Si}$ and Ge-embedded graphene [18], their DFT calculations

\footnotetext{
* Corresponding author. Tel.: +86-68418359; fax: +86-68418359

E-mail address: daigl@tzc.edu.cn (G. Dail)
}

indicate that for the $\mathrm{CO}$ oxidation, the ER mechanism to be the most favorable channel, and all these materials can be used as excellent and low-cost catalysts due to relatively high catalytic ability for the $\mathrm{CO}$ oxidation.

As typical first and second-row early transition metals, titanium and zirconium have good catalytic activity toward many types of reactions. From our previous theoretical study [25-28], we found the naked titanium cation has strong catalytic performance of activating the $\mathrm{C}-\mathrm{S}$ and $\mathrm{C}-\mathrm{O}$ bonds in SCO molecule [25], zirconium atom shows good ability toward the activation of $\mathrm{C}-\mathrm{O}, \mathrm{C}-\mathrm{H}$, and $\mathrm{C}-\mathrm{C}$ bonds in carbon dioxide, acetone and acetaldehyde [26-28]. Recently, Krasheninnnikov et al. presented a DFT study of transition-metal atoms embedded in vacancy in a graphene [29], they found the bonding is very strong and the migration barrier of metal atoms on a single vacancy of metal-embedded complexes are relatively high. The metals-embedded graphene would be stable enough to be utilized in catalysis applications. To the best of our knowledge, there is no relative report on the mechanisms of the $\mathrm{CO}$ oxidation reaction over $\mathrm{Ti}$ and $\mathrm{Zr}$-embedded graphene. Therefore, the research on $\mathrm{CO}$ oxidation over typical early metal-embedded graphene has important theoretical and experimental significances. The calculated results are expected to forecast further experimental findings and to provide some valuable reference for designing of graphene-based catalysts for monitoring and removing toxic gases.

\section{METHODOLOGY}

To understand the detailed reaction mechanism at the molecular level, quantum chemical calculations were performed in this study. All the geometries involved in the reaction were optimized by employing the B3LYP density functional theory method as implemented in the Gaussian09 program package [30, 31]. In all calculations, the effective core potentials (ECP) of Stuttgart basis set 
was used for the zirconium, the $5 s$ and $4 d$ in zirconium were treated explicitly by a $(8 s 7 p 6 d)$ Gaussian basis set contracted to $(6 s 5 p 3 d)$ [32]. For Ti and non-metal atoms, a standardized 6-31G $(d)$ basis set was used. Previous investigation proved that this method is an effective way to explore the graphene properties [33]. The nature of the stationary point was verified through a vibrational analysis (no imaginary frequencies). A hexagonal graphene super cell ( $4 \times 4$ graphene unit cell) containing 48 carbon atoms was chosen as the basic model for the calculations. A similar model used in previous theoretical study by Esrafili et al. has got satisfied results [18]. The metal-embedded graphene was then modeled by substituting a single metal atom with one carbon atom on the surface. The adsorption energy $\left(E_{a d s}\right)$ is calculated as:

$E_{\text {ads }}=E($ adsorbate-substrate $)-\left(E_{\text {adsorbate }}+E_{\text {substrate }}\right)$,

where a negative $E_{a d s}$ indicates exothermic process. Electron density difference (EDD) was conducted using MultiWFN program package [34].

\section{RESULTS AND DISCUSSION}

\subsection{Ti and Zr-embedded graphene}

When the metal atom is placed above a vacancy in graphene, it moves outward the plane of graphene due to its relatively larger atomic radius than the carbon atom after geometry optimization. As it is clear from the structure of Ti and Zr-embedded graphene (IM0) in Fig. 1, the average bond length of metal atom with its neighboring carbon atoms are 1.928 and $2.039 \AA$ respectively, which are about 0.518 and $0.629 \AA$ larger than the average $\mathrm{C}-\mathrm{C}$ bond length in the pristine graphene.
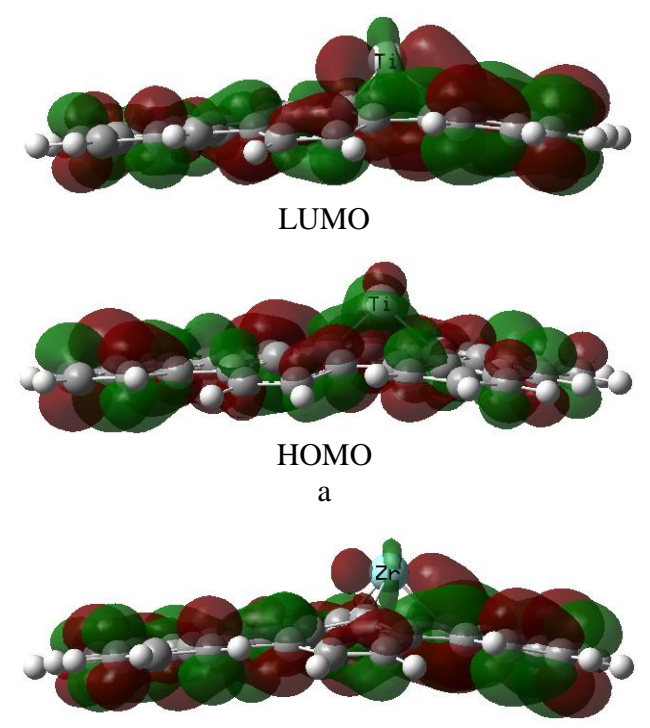

LUMO

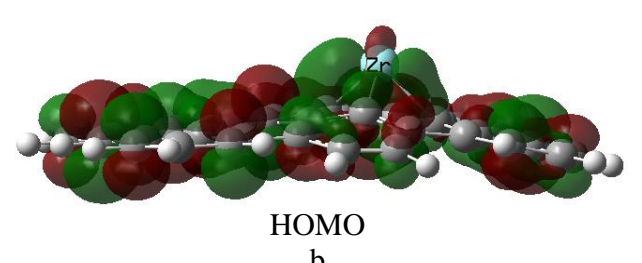

b

Fig. 1. $a-$ frontier molecular orbits of the Ti-embedded graphene; $\mathrm{b}$ - frontier molecular orbits of the $\mathrm{Zr}$-embedded graphene
The calculated adsorption energy of the metal atom over the vacancy site of the graphene are -145.4 and $-179.8 \mathrm{kcal} / \mathrm{mol}$ for $\mathrm{Ti}$ and $\mathrm{Zr}$ respectively, indicating a strong interaction between the dopant atoms and the surface. To gain deeper insight into the significant enhancement of metal adsorption at the graphene vacancy site, we plotted the frontier molecular orbits of IM0. The calculated electronic structures of the molecular orbits are shown in Fig. 1. Both the HOMO and LUMO locate on the metal atom dominantly, the electron clouds of the lowest unoccupied molecular orbits (LUMO) for the compound illustrate the strong $d$-orbital characteristics of metal atom allowing an incoming electron to occupy this state. All of these observations demonstrate that the metal atom might be the activate site for adsorbing an electrophile probe molecule. To further analyze the intermolecular interactions, the geometries of metal-embedded graphene were used to perform NBO analysis [35]. The result shows that about 1.236 and $1.203 \mathrm{e}$ (for $\mathrm{Ti}$ and $\mathrm{Zr}$ respectively) are transferred from metal atoms to the adjacent carbon atoms that lead to the strong bonding between metal atoms and their neighbors, due to the electronegativity difference between metal and carbon atoms. The strong electron interaction between metal atoms and surface moiety facilitate the transfer of electron in metal-embedded graphene composite. The NBO result indicates that the graphene sheet act as an electron withdrawing support. In addition, this can suggest that both the $\mathrm{Ti}$ and $\mathrm{Zr}$ atoms are activated to be more electrophilic by their support. For metal-embedded graphene composite molecule the calculated MESP map displays the electrophilic region near the metal center. The more positively charged metal atoms are expected to have a stronger interaction with the adsorption gas molecule. In the next section, the adsorption behaviors of $\mathrm{O}_{2}$ and $\mathrm{CO}$ on the metal-embedded graphene and the catalytic oxidation processes for the $\mathrm{CO}$ will be discussed.

\subsection{Adsorption of $\mathrm{O}_{2}$ and $\mathrm{CO}$ molecules over Ti- embedded graphene}

Previous studies have been established that there are two possible mechanisms for $\mathrm{CO}$ oxidation, namely the Eley-Rideal (ER) mechanism and Langmuir-Hinshelwood (LH) mechanism [15]. In the ER mechanism, the $\mathrm{O}_{2}$ molecule is firstly absorbed over the catalyst surface, then the $\mathrm{CO}$ approaches the activated $\mathrm{O}_{2}$ to form $\mathrm{CO}_{2}$. This reaction mode is quite different from the later, as in the $\mathrm{LH}$ mechanism, both $\mathrm{O}_{2}$ and $\mathrm{CO}$ molecules co-adsorb on the surface and to generate $\mathrm{CO}_{2}$ directly. But many previous studies indicate that it is almost impossible for the $\mathrm{CO}$ oxidation over metal-embedded graphene through LH mechanism. So, in the present study we emphasize the ER mechanism only.

First, we will discuss the reaction over Ti-embedded graphene. The adsorption structures on the Ti-embedded graphene are described in Fig. 1 a. For $\mathrm{O}_{2}$, the most energetically favorable configuration (IM1) is characterized by $\mathrm{O}_{2}$ parallel to the graphene surface forming two chemical bonds with the $\mathrm{Ti}$ atom, the calculated adsorption energy is $-56.19 \mathrm{kcal} / \mathrm{mol}$. According the NBO analysis, about $0.759 \mathrm{e}$ charge is 
transferred from Ti-embedded graphene to $\mathrm{O}_{2}$, which could occupy the antibonding $\pi^{*}$ orbital of $\mathrm{O}_{2}$ and subsequently lead to the elongation of the $\mathrm{O}-\mathrm{O}$ bond from 1.215 to $1.477 \AA$. The electron density difference (EDD) plots of the adsorbed configurations are depicted in Fig. 2, in which the full and dotted lines are related to the electron density accumulation and depletion areas respectively.

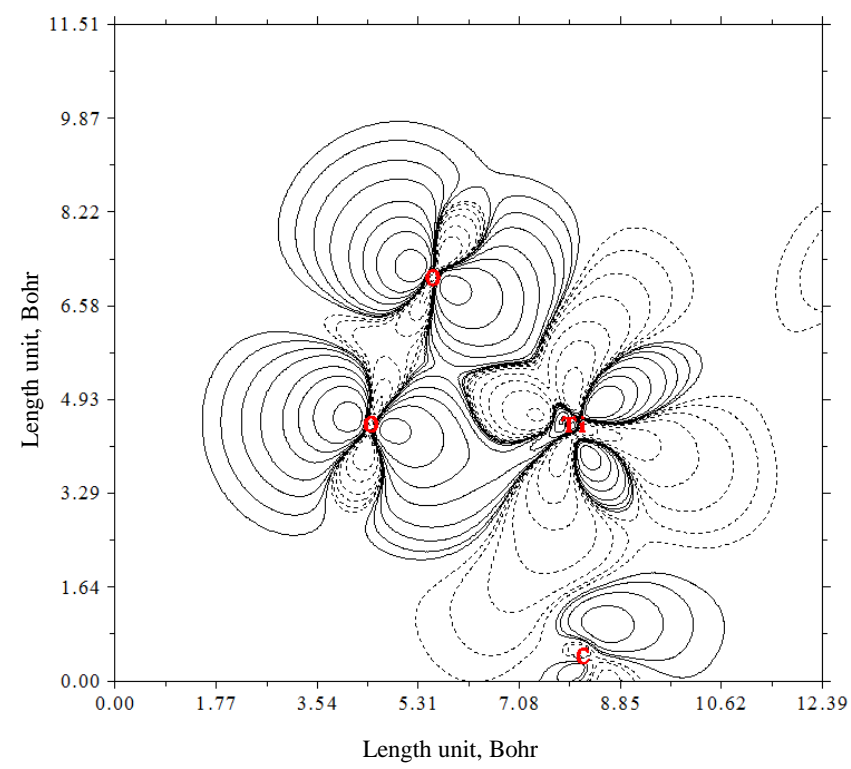

Fig. 2. Electron density difference (EDD) between the $\mathrm{O}_{2}$ adsorption state and Ti-embedded graphene (the electron density depletion and accumulation sites are displayed in dashed and solid lines respectively)

The EDD plot shows the charge transfer from the Tiembedded graphene to the $\mathrm{O}_{2}$, and the accumulation of electron density at the two $\mathrm{Ti}-\mathrm{O}$ bonds. The EDD plot agrees well with the result of NBO analysis. With respect to the $\mathrm{CO}$, its adsorption behavior over Ti-embedded graphene plays an very important role in the following oxidation reaction. Calculation indicates the $\mathrm{CO}$ can also be adsorbed on the Ti-embedded graphene easily in the $\mathrm{OC}-\mathrm{Ti}$ adsorbing direction with the adsorption energy of $-20.63 \mathrm{kcal} / \mathrm{mol}$, the calculated distance between $\mathrm{Ti}$ and $\mathrm{C}$ is $2.240 \AA$, and only $0.044 \mathrm{e}$ charge is transferred from CO to the surface. The above results reveal that both $\mathrm{O}_{2}$ and $\mathrm{CO}$ have strong interactions with Ti-embedded graphene, but it is clear that $\mathrm{O}_{2}$ has even more favorable binding energy. So we believe that if a mixture of $\mathrm{O}_{2} / \mathrm{CO}$ is injected as the reaction gas, the Ti site will be covered by the adsorbed $\mathrm{O}_{2}$ molecule dominantly.

\subsection{Oxidation of $\mathrm{CO}$ by $\mathrm{O}_{2}$ over the Ti-embedded graphene}

The reaction mechanism is proposed in stepwise reactions, which are the activation of $\mathrm{O}_{2}$ and followed by the oxidation of $\mathrm{CO}$ as presented in Eq. 2-Eq. 4:

The adsorption and activation of $\mathrm{O}_{2}$ :

$\mathrm{O}_{2} \rightarrow \mathrm{O}_{2 \text { act }}$;

The adsorption and oxidation of $\mathrm{CO}$ :

$\mathrm{O}_{2 \mathrm{act}}+\mathrm{CO} \rightarrow \mathrm{CO}_{2}+\mathrm{O}_{\text {ads }}$;

$\mathrm{O}_{\mathrm{ads}}+\mathrm{CO} \rightarrow \mathrm{CO}_{2}$.
The activation reaction starts with the formation of the $\mathrm{O}_{2}$-bound encounter complex IM1, which is $-56.19 \mathrm{kcal} / \mathrm{mol}$ below the entrance channel $\mathrm{IM} 0+\mathrm{O}_{2}$. Starting from IM1, it can rearrange to form IM2, which undergoes a rupture of $\mathrm{O}-\mathrm{O}$ bond via a transition state $\mathrm{TS}_{12}$ that is $27.65 \mathrm{kcal} / \mathrm{mol}$ above IM1. As shown in Fig. $1 \mathrm{a}$, the distance between two oxygen atoms is elongated by $0.587 \AA$. This fact indicates that the weak electrostatic interaction between $\mathrm{Ti}$ and $\mathrm{O}_{2}$ has strengthened when it is converted into $\mathrm{TS}_{12}$. The distances between $\mathrm{Ti}$ atom and two oxygen atoms are shortened from 1.850 to $1.720 \AA$ and 1.827 to $1.778 \AA$ respectively, which suggests that the two $\mathrm{Ti}-\mathrm{O}$ bonds is forming. Simultaneously, the activated $\mathrm{O}-\mathrm{O}$ bond is almost broken, and the bond length is elongated to $2.064 \AA$. The imaginary frequency of $\mathrm{TS}_{12}$ is $-504.1 i \mathrm{~cm}^{-1}$, and the normal mode corresponds to the rupture of $\mathrm{O}-\mathrm{O}$ bond with the result of $\mathrm{Ti}$ atom inserting into $\mathrm{O}-\mathrm{O}$ bond. The inserted complex IM2 is $-53.79 \mathrm{kcal} / \mathrm{mol}$ lower in energy than the reactants (see Fig. 3 a), As shown in Fig. 1 a, the $\mathrm{O}-\mathrm{O}$ bond length in IM2 is elongated to $2.670 \AA$, which means this bond has ruptured thoroughly. The large amount of energy gained in the formation of the IM1 can drive the cleavage process complete easily. Clearly, the Tiembedded graphene can activate adsorbed oxygen effectively. From the NBO analysis, during the reaction process from IM1 to IM2, about 0.576 e negative charge on graphene is transferred to $\mathrm{Ti}$ atom and oxygen molecule. In IM2, the electron transferring from the Ti-embedded graphene increases the negative charge on the two adsorbed oxygen atoms from -0.759 to -1.175 e, at the same time, the positive charge on the $\mathrm{Ti}$ atom is decreased from 1.257 to $1.097 \mathrm{e}$. Obviously, from IM0 to IM2, the oxygen atom pulls the charge from the surface owing to its strong electronegativity, and the Ti-graphene substrate acts as the electron donor during the process of oxygen activation, while the titanium atom acts as the bridge of transferring electron due to only a negligible charge $(0.139 \mathrm{e})$ is transferred on it from IM0 to IM2.

As shown in Fig. $3 \mathrm{~b}$, the first oxidation reaction channel starts with the formation of an encounter complex IM3, along this reaction pathway, the carbon atom can insert into the activated $\mathrm{O}-\mathrm{O}$ bond. From Fig. 1 a, one can see the distances between the carbon atom and the two oxygen atoms in IM3 are 1.366 and $1.352 \AA$ respectively, this indicates that the two $\mathrm{C}-\mathrm{O}$ bonds are forming. Simultaneously, from Fig. 1 a, the distances between $\mathrm{Ti}$ and two $\mathrm{O}$ atoms in IM3 are lengthened to 1.914 and $1.966 \AA$ respectively. Along this reaction coordinate, one of the $\mathrm{Ti}-\mathrm{O}$ bonds and a $\mathrm{C}-\mathrm{O}$ bond rupture simultaneously to form IM4, with an energy barrier of $28.65 \mathrm{kcal} / \mathrm{mol}$. From Fig. $3 \mathrm{~b}$, one can see that via the transition state $\mathrm{TS}_{34}$, the $\mathrm{CO}_{2}$ molecule is generated and one activated atomic oxygen remains on the $\mathrm{Ti}$ site of the surface to form IM5. The binding energy between $\mathrm{CO}_{2}$ and IM5 is calculated to be $6.69 \mathrm{kcal} / \mathrm{mol}$. Obviously, from Fig. 3 b, this $\mathrm{CO}$ oxidation channel $\mathrm{IM} 2+\mathrm{CO} \rightarrow \mathrm{IM} 5+\mathrm{CO}_{2}$ is spontaneous in energy, and exothermic by $5.78 \mathrm{kcal} / \mathrm{mol}$. It should be pointed out that although several trials were undertaken to search for possible transition states that connect reactants and IM3, 
no such structures were obtained. Obviously, the formation of IM3 is a barrier-free exothermic reaction.

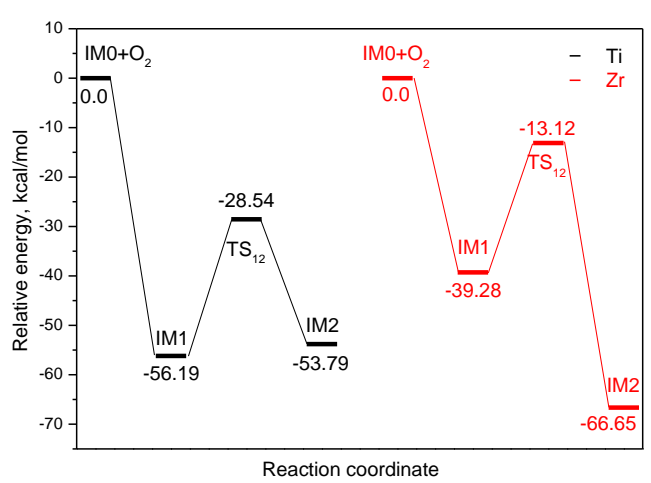

a

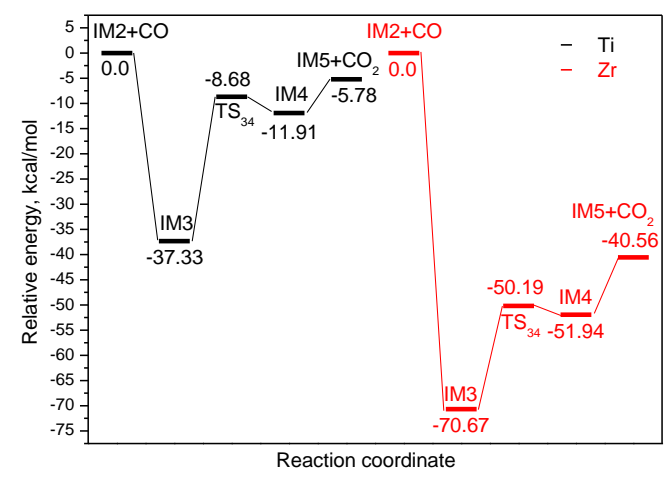

b

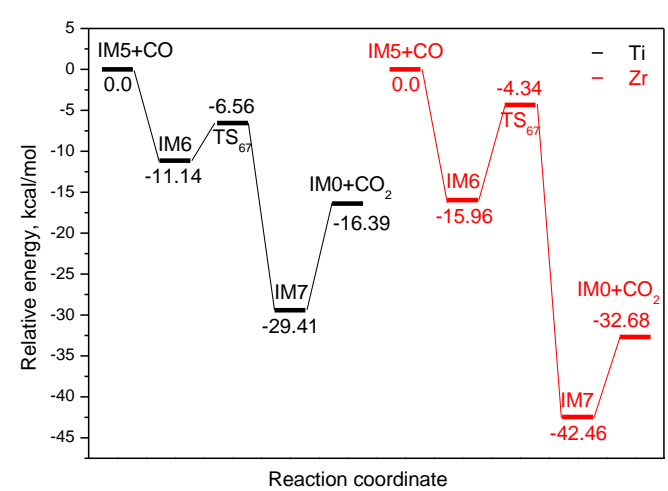

c

Fig. 3. Potential energy surface profiles for the reactions: $\mathrm{a}-\mathrm{O}_{2} \rightarrow \mathrm{O}_{2 \text { act }} ; \mathrm{b}-\mathrm{O}_{2 \text { act }}+\mathrm{CO} \rightarrow \mathrm{CO}_{2}+\mathrm{O}_{\text {ads }}$ $\mathrm{c}-\mathrm{O}_{\mathrm{ads}}+\mathrm{CO} \rightarrow \mathrm{CO}_{2}$

The NBO analysis shows the molecular charge of the $\mathrm{CO}$ is increased from neutral in free molecule to $0.395 \mathrm{e}$ in IM3, whereas the total charge of the graphene is decreased from $0.078 \mathrm{e}$ in IM2 to $-0.533 \mathrm{e}$ in IM4. Interestingly, during the whole process of $\mathrm{CO}$ oxidation from IM2 to IM4, the atomic positive charge of the $\mathrm{Ti}$ atom is changed indistinctively (from 1.097 to $1.159 \mathrm{e}$ ). Obviously, when the gas phase $\mathrm{CO}$ reacts with the pre-adsorbed $\mathrm{O}_{2}$, the graphene sheet acts as the electron acceptor during the oxidation process, this is quite different from that of $\mathrm{O}_{2}$ activation over Ti-graphene surface, in that case, the substrate acts as the role of electron donor. In IM4, the $\mathrm{CO}_{2}$ molecule can desorb from the surface of catalyst to form the O-Ti-graphene (IM5) easily. Due to its strong electronegativity, the oxygen atom in IM5 can easily pull the charge from Ti. The NBO analysis shows in IM5, there is $1.244 \mathrm{e}$ on the $\mathrm{Ti}$ atom, $-0.648 \mathrm{e}$ on the $\mathrm{O}$ atom, suggesting that the $\mathrm{Ti}-\mathrm{O}$ site might be the active site for adsorbing and oxidation an probe molecule, such as CO.

Now we will discuss the second $\mathrm{CO}$ oxidation channel, which may lead to product $\left(\mathrm{CO}_{2}+\mathrm{IM} 0\right)$ formation. As described in Fig. 3 c, this route starts with the adsorption of $\mathrm{CO}$ on both $\mathrm{O}$ and $\mathrm{Ti}$ sites of the O-Ti-graphene (IM5), formation of a three-membered ring structure, IM6. NBO analysis of this complex shows there exist strong interaction between the $4 d$ orbital of $\mathrm{Ti}$ and the $\pi^{*}$ orbital of $\mathrm{C}-\mathrm{O}$ bond, and the $\mathrm{Ti}$ can receive some electron from CO. Energetically, IM6 lies $-11.14 \mathrm{kcal} / \mathrm{mol}$ lower than the separate reactants of CO + IM5, and the formation of IM6 is a barrier-free exothermic reaction. Along the reaction channel, the next step corresponds to the $\mathrm{CO}_{2}$ formation followed by the non-reactive-dissociation. Throughout a transition state $\mathrm{TS}_{67}$, the intermediate complex IM7 is yielded at last with an activation barrier of $11.37 \mathrm{kcal} / \mathrm{mol}$. Geometrically, the $\mathrm{C}-$ Oads bond in $\mathrm{TS}_{67}$ is shortened to $1.793 \AA$, synchronously, the distance between $\mathrm{Ti}$ and Oads is elongated to $1.758 \AA$, The imaginary frequency of $\mathrm{TS}_{67}$ is $336.8 i \mathrm{~cm}^{-1}$, and the normal mode corresponds to the formation of $\mathrm{C}-\mathrm{O}$ bond. One exit channel of IM7 is direct desorption of $\mathrm{CO}_{2}$ to yield the product $\left(\mathrm{CO}_{2}+\mathrm{IM} 0\right)$, but this is a greatly endothermic process with the desorption energy of $13.02 \mathrm{kcal} / \mathrm{mol}$. Obviously, the surface of catalyst can be recovered after second CO oxidation. During the process of second $\mathrm{CO}$ oxidation, the graphene support plays an important role in the chemical properties for the Ti-embedded graphene, the negative charge of $-0.548 \mathrm{e}$ can be lowered to $-1.278 \mathrm{e}$ by electron transfer from the adsorption of CO. Similar to the first $\mathrm{CO}$ oxidation, the graphene act as an electron withdrawing group here.

\subsection{The reaction over the $\mathrm{Zr}$-embedded graphene}

In addition, we also located possible $\mathrm{CO}$ oxidation channels on the $\mathrm{Zr}$-embedded graphene. As shown in Fig. 3, the reaction mechanism on this surface is in general similar to that of the Ti-embedded one. The reaction starts with an oxygen molecular activation, followed by two possible $\mathrm{CO}$ oxidation pathways to form $\mathrm{CO}_{2}$. In both cases, as all the intermediates, transition states and products involved in the reaction lie below the respective reactants, the reactions over $\mathrm{Ti}$ and $\mathrm{Zr}$-embedded graphene are expected to occur spontaneously in energy. From Fig. $3 \mathrm{a}$, one can see for the $\mathrm{O}_{2}$ activation over Tiembedded graphene, both the initial intermediate (IM1), and transition state $\left(\mathrm{TS}_{12}\right)$ involved in the reaction, lie far below the analogues over the $\mathrm{Zr}$-embedded one, we believe the Ti-embedded graphene can activate oxygen more effectively. But, for the next $\mathrm{CO}$ oxidation over surface with oxygen adsorption and $\mathrm{O}-\mathrm{Zr}$-graphene, the oxidation pathways are almost energetically preferable with respect to the corresponding routes over $\mathrm{Ti}$. Obviously, $\mathrm{Zr}$ embedded graphene appears to be more effective during the process of $\mathrm{CO}$ oxidation. 


\section{CONCLUSIONS}

In the present study, the oxidation reactions of $\mathrm{O}_{2}$ and $\mathrm{CO}$ over $\mathrm{Ti}$ and $\mathrm{Zr}$-embedded graphene have been investigated detailedly. The reactions are expected to occur using the ER mechanism. For investigating the CO oxidation over $\mathrm{Ti}$ and $\mathrm{Zr}$-embedded graphene in the presence of $\mathrm{O}_{2}$, a possible reaction is found and it includes the following steps.

$\mathrm{O}_{2} \rightarrow \mathrm{O}_{2 \text { act }}$;

$\mathrm{O}_{2 \text { act }}+\mathrm{CO} \rightarrow \mathrm{CO}_{2}+\mathrm{O}_{\text {ads }}$;

$\mathrm{O}_{\mathrm{ads}}+\mathrm{CO} \rightarrow \mathrm{CO}_{2}$.

The catalyst substrate acts both the electron donor and acceptor during different reaction processes. The present theoretical work is a beneficial complement to the oxidation reaction of $\mathrm{CO}$ over metal-embedded graphene, which plays an important role in promoting further experimental efforts to design novel catalysts for solving the environmentally harmful exhaust gases from industrial waste.

\section{Acknowledgements}

This work was supported by the Jiangsu Overseas Visiting Scholar program for University Prominent Young and Middle-aged Teachers and Presidents, National University of Innovative Pilot Projects (201610332014), National Science Foundations of China (21203135) and the Natural science research project of Anhui Province (KJ2015B08). The computing center for Fudan University is thanked for computer time.

\section{REFERENCES}

1. Royer, S., Duprez, D. Catalytic Oxidation of Carbon Monoxide Over Transition Metal Oxides ChemCatChem 3 2011: pp. $24-65$. https://10.1021/ja9836161

2. Lu, Y.H., Zhou, M., Zhang, C., Feng, Y.P. Metalembedded Graphene: A Possible Catalyst with High Activity The Journal of Physical Chemistry $C \quad 113$ 2009: pp. 20156-20160. https://doi.org/10.1021/jp908829m

3. Hendriksen, B., Frenken, J. CO Oxidation on Pt (110): Scanning Tunneling Microscopy Inside A High-pressure Flow Reactor Physical Review Letters 89 2002: pp. 046101. https://doi.org/10.1103/PhysRevLett.89.046101

4. Su, H.Y., Yang, M.M., Bao, X.H., Li, W.X. The Effect of Water on the CO Oxidation on $\mathrm{Ag}$ (111) and $\mathrm{Au}$ (111) Surfaces: A First-principle Study The Journal of Physical Chemistry C 112 2008: pp. 17303-17310. https://doi.org/10.1021/jp803400p

5. Liu, W., Zhu, Y., Lian, J., Jiang, Q. Adsorption of CO on Surfaces of $4 \mathrm{~d}$ and 5d Elements in Group VIII The Journal of Physical Chemistry C 111 2007: pp. $1005-1009$. https://doi.org/10.1021/jp0661488

6. Liu, D.J. CO Oxidation on Rh (100): Multisite Atomistic Lattice-gas Modeling The Journal of Physical Chemistry C 111 2007: pp. $14698-14706$. https://doi.org/10.1021/jp071944e
7. Wallace, W.T., Whetten, R.L. Coadsorption of $\mathrm{CO}$ and $\mathrm{O}_{2}$ on Selected Gold Clusters: Evidence for Efficient Roomtemperature $\mathrm{CO}_{2}$ Generation Journal of American Chemical Society 124 2002: pp. 7499-7505. https://doi.org/10.1021/ja0175439

8. Chang, C.M., Cheng, C., Wei, C.M. CO Oxidation on Unsupported $\mathrm{Au}_{55}, \mathrm{Agg}_{55}$, and $\mathrm{Au}_{25} \mathrm{Ag}_{30}$ Nanoclusters The Journal of Chemical Physics 128 2008: pp. 124710. https://doi.org/10.1063/1.2841364

9. Molina, L., Hammer, B. Active Role of Oxide Support During CO Oxidation at $\mathrm{Au} / \mathrm{MgO}$ Physical Review Letters 90 2003: p. 206102. https://doi.org/10.1103/PhysRevLett.90.206102

10. Esrafili, M.D., Nematollahi, P., Nurazar, R. Pd-embedded Graphene: An Efficient and Highly Active Catalyst for Oxidation of CO Superlattice \& Microstructures 92 2016: pp. $60-67$.

https://doi.org/10.1016/j.spmi.2016.02.006

11. Huang, C., Ye, X., Chen, C., Lin, S., Xie, D. A Computational Investigation of $\mathrm{CO}$ Oxidation on Ruthenium-embedded Hexagonal Boron Nitride Nanosheet Computational and Theoretical Chemistry 1011 2013: pp. 5-10. https://doi.org/10.1016/j.comptc.2013.02.004

12. Tang, Y., Yang, Z., Dai, X. A Theoretical Simulation on the Catalytic Oxidation of $\mathrm{CO}$ on Pt/graphene Physical Chemistry Chemical Physics 14 2012: pp. 16566-16572. https://dx.doi.org/10.1039/C2CP42822A

13. Du, J., Wu, G., Wang, J. Density Functional Theory Study of the Interaction of Carbon Monoxide with Bimetallic CoMn Clusters The Journal Physical Chemistry A 114 2010: pp. $10508-10514$. https://doi.org/10.1021/jp106321s

14. Li, Y.F., Zhao, J.J., Chen, Z.F. Fe-anchored Graphene Oxide: A Low-cost and Easily Accessible Catalyst for Lowtemperature $\mathrm{CO}$ Oxidation The Journal of Physical Chemistry C 116 2012: pp. 2507-2514.

https://doi.org/10.1021/jp209572d

15. Li, Y., Zhou, Z., Yu, G., Chen, W., Chen, Z. CO Catalytic Oxidation on Iron-embedded Graphene: Computational Quest for Low-cost Nanocatalysts The Journal of Physical Chemistry C 114 2010: pp. 6250-6254. https://doi.org/10.1021/jp911535v

16. Wannakao, S., Nongnual, T., Khongpracha, P., Maihom, T., Limtrakul, J. Reaction Mechanisms for CO Catalytic Oxidation by $\mathrm{N}_{2} \mathrm{O}$ on Fe-embedded Graphene The Journal of Physical Chemistry $C 116$ 2012: pp. $16992-16998$. https://doi.org/10.1021/jp3035192

17. Zhao, P., Su, Y., Zhang, Y., Li, S.J., Chen, G. CO Catalytic Oxidation on Iron-embedded Hexagonal Boron Nitride Sheet Chemical Physics Letters 515 2011: pp. $159-162$. https://doi.org/10.1016/j.cplett.2011.09.034

18. Esrafili, M.D, Nematollahi, P., Abdollahpour, H. A Comparative DFT Study on the CO Oxidation Reaction over Al- and Ge-embedded Graphene as Efficient Metal-free Catalysts Applied Surface Science 378 2016: pp. $418-425$ https://doi.org/10.1016/j.apsusc.2016.04.012

19. Song, E.H., Wen, Z., Jiang, Q. CO Catalytic Oxidation on Copper-embedded Graphene The Journal of Physical Chemistry C 115 2011: pp. 3678-3683. https://doi.org/10.1021/jp108978c 
20. Wang, L., Luo, Q., Zhang, W., Yang, J. Transition Metal Atom Embedded Graphene for Capturing CO: A Firstprinciples Study International Journal of Hydrogen Energy 39 2014: pp. 20190-20196.

https://doi.org/10.1016/j.ijhydene.2014.10.034

21. Zhao, J.X., Chen, Y., Fu, H.G. Si-embedded Graphene: An Efficient and Metal-free Catalyst for $\mathrm{CO}$ Oxidation by $\mathrm{N}_{2} \mathrm{O}$ or $\mathrm{O}_{2}$ Theoretical Chemistry Accounts 131 2012: pp. $1242-1252$.

https://doi.org/10.1007/s00214-012-1242-7

22. Tang, Y.N., Liu, Z.Y., Dai, X.Q., $\quad$ Yang, Z.X., Chen, W.G., Ma, D.W., Lu, Z.S. Theoretical Study on the Si-doped Graphene as an Efficient Metal-free Catalyst for CO oxidation Applied Surface Science 308 2014: pp. $402-407$. https://doi.org/10.1016/j.apsusc.2014.04.189

23. Oubal, M., $\quad$ Picaud, S., $\quad$ Rayez, M.T., $\quad$ Rayez, J.C. Adsorption of Atmospheric Oxidants at Divacancy Sites of Graphene: A DFT Study Computational and Theoretical Chemistry 1016 2013: pp. 22-27. https://doi.org/10.1016/j.comptc.2013.04.017

24. Wanno, B., Tabtimsai, C. A DFT Investigation of CO Adsorption on VIIIB Transition Metal-doped Graphene Sheets Superlattices \& Microstructures 67 2014: pp. $110-117$. https://doi.org/10.1016/j.spmi.2013.12.025

25. Dai, G.L., Fan, K.N. Theoretical Study of The Reaction of $\mathrm{Ti}^{+}$with SCO in Gas Phase Journal of Molecular Structure: THEOCHEM 806 2007: pp. 261-268. https://doi.org/10.1016/j.theochem.2006.12.003

26. Dai, G.L., Wang, C.F., Chen, H., Wu, J.Y., Yan, H., Zhong, A.G. Theoretical Study on the Reactions of $\mathrm{Zr}^{+}$and $\mathrm{Zr}$ with $\mathrm{CO}_{2}$ in Gas Phase Russian Journal of Physical Chemistry A 84 2010: pp. 2238-2246. https://doi.org/10.1134/S0036024410130066

27. Dai, G.L., Wang, C.F., Wu, J.Y., Zhong, A.G. Reaction of acetaldehyde with Zirconium: A Density Functional Theoretical Study Computational and Theoretical Chemistry 965 2011: pp. 60-67. https://doi.org/10.1016/j.comptc.2011.01.024

28. Jin, Y.X., Dai, G.L., Wu, J.Y., Wang, C.F. Theoretical Survey of the Potential Energy Surface of $\mathrm{Zr}+$ acetone Reaction Computational and Theoretical Chemistry 976 2011: pp. $120-129$. https://doi.org/10.1016/j.comptc.2011.08.012

29. Krasheninnikov, A.V., Lehtinen, P.O., $\quad$ Foster, A.S., Pyykko, P., Nieminen, R.M. Embedding Transition-Metal Atoms in Graphene: Structure, Bonding, and Magnetism Physical Review Letters 102 2009: pp. 126807.
https://doi.org/10.1103/PhysRevLett.102.126807

30. Becke, A.D. A New Mixing of Hartree-Fock and Local Density-functional Theories Journal of Chemical Physics 98 1993: pp. $1372-1377$. https://doi.org/10.1063/1.464304

31. Frisch, M.J., $\quad$ Trucks, G.W., $\quad$ Schlegel, H.B., Scuseria, G.E., Robb, M.A., Cheeseman, J.R., Montgomery, Jr.J.A., $\quad$ Vreven, T., Kudin, K.N., Burant, J.C., Millam, J.M., Iyengar, S.S., Tomasi, J., Barone, V., Mennucci, B., Cossi, M., Scalmani, G., Rega, N., Petersson, G.A., Nakatsuji, H., Hada, M., Ehara, M., Toyota, K., Fukuda, R., Hasegawa, J., Ishida, M., Nakajima, T., Honda, Y., Kitao, O., Nakai, H., $\quad$ Klene, M., $\quad$ Li, X., $\quad$ Knox, J.E., Hratchian, H.P., Cross, J.B., Adamo, C., Jaramillo, J., Gompert, R., Stratmann, R.E., Yazyev, O., Austin, A.J., Cammi, R., Pomelli, C., Ochterski, J.W., Ayala, P.Y., Morokuma, K., $\quad$ Voth, G.A., $\quad$ Salvador, P., Dannenberg, J.J., Zakrzewski, V.G., $\quad$ Dapprich, S., Daniels, A.D., Strain, M.C., Farkas, O., Malick, D.K., Rabuck, A.D., $\quad$ Raghavachari, K., $\quad$ Foresman, J.B., Ortiz, J.V., Cui, Q., Baboul, A.G., Clifford, S., Cioslowski, J., Stefanov, B.B., Liu, G., Liashenko, A., Piskorz, P., Komaromi, I., Martin, R.L., Fox, D.J., Keith, T., Al-Laham, M.A., $\quad$ Peng, C.Y., Nanayakkara, A., Challacombe, M., Gill, P.M.W., Johnson, B., Chen, W., Wong, M.W., Gonzalez, C., Pople, J.A. Gaussian 09, Revision C.01, Gaussian Inc, Wallingford CT 2010.

32. Andrae, D., Häußermann, U., Dolg, M., Stoll, H., Preub, H. Energy-adjusted $a b$ initio Pseudopotentials for the Second and Third Row Transition Elements Theoretical Chemistry Accounts 77 1990: pp. 123-141. https://doi.org/10.1007/BF01114537

33. Zhao, W.H., Yang, L.J., Qing, L.H., Lv, X.M., Yi, L.Y., Li, H., Chen, Z.Q. The Strong Effect of Substituents on the Carbonyl Reduction in Graphene Oxide: A DFT study Computational and Theoretical Chemistry 1068 2015: pp. $1-7$. https://doi.org/10.1016/j.comptc.2015.06.009

34. Lu, T., Chen, W.F. Multiwfn: A Multifunctional Wavefunction Analyzer Journal of Computational Chemistry 33 2012: pp. 580-592. https://doi.org/10.1002/jcc. 22885

35. Reed, A.E., Curtiss, L.A., Weinhold, F. Intermolecular Interactions From a Natural Bond Orbital, Donor-acceptor Viewpoint Chemical Review 88 1988: pp. 899-926. https://doi.org/10.1021/cr00088a005 